Check for updates

Cite this: RSC Adv., 2022, 12, 2036

Received 16th October 2021

Accepted 19th December 2021

DOI: 10.1039/d1ra07663a

rsc.li/rsc-advances

\section{Optimization and characterization of biosurfactant produced by indigenous Brevibacillus borstelensis isolated from a low permeability reservoir for application in MEOR $\uparrow$}

\author{
Hao Dong, (DD a Anying Zheng, ${ }^{\mathrm{b}}$ Yanlong He, ${ }^{\mathrm{c}}$ Xiaotong Wang, (D) de Yang $\mathrm{Li}^{\mathrm{b}}$ \\ Gaoming Yu, ${ }^{b}$ Yongan Gu, ${ }^{b}$ I. M. Banat, ${ }^{f}$ Shanshan Sun, ${ }^{b}$ Yuehui She ${ }^{* b}$ \\ and Fan Zhang 1 * *g
}

\begin{abstract}
Biosurfactants are expected to be a key factor for microbial enhanced oil recovery (MEOR). In this study, we described the novel biosurfactant-producing strain Brevibacillus borstelensis YZ-2 isolated from a low permeability oil reservoir. We purified and characterized the biosurfactants produced by this YZ-2 strain via thin-layer chromatography and MALDI-TOF-MS, revealing them to be fengycins. We additionally used a Box-Behnken design approach to optimize fermentation conditions in order to maximize the biosurfactants production. Core flooding experiments showed that biosurfactants produced by YZ-2 can significantly enhance crude oil recovery. Micro-model tests showed that emulsification and IFT reduction was the main EOR mechanism of the YZ biosurfactant in the oil wet model. In summary, these findings highlight the potential of Brevibacillus borstelensis YZ-2 and its metabolites for MEOR.
\end{abstract}

\section{Introduction}

Microbial enhanced oil recovery (MEOR) has been a topic of increasing academic and industrial interest owing to the fact that it has the potential to simultaneously be environmentally friendly and cost-effective., ${ }^{\mathbf{1} 2}$ MEOR is a technique wherein microbes and their metabolites are applied to oil reservoirs in a manner that results in improved oil recovery. ${ }^{3-6}$ Several studies to date have found that biosurfactant-producing microbes play a key role in the MEOR process. ${ }^{7,8}$ Biosurfactants are able to emulsify crude oil and to reduce the interfacial tension (IFT) between oil and water, thereby leading to increased crude oil fluidity. ${ }^{9}$

${ }^{a}$ College of Chemistry and Environmental Engineering, Yangtze University, Jingzhou 434023, China

${ }^{b}$ College of Petroleum Engineering, Yangtze University, Wuhan, Hubei 430010, China. E-mail:sheyuehui@163.com

${ }^{c}$ College of Petroleum Engineering, Xi'an Shiyou University, Xi'an 710065, China

${ }^{d}$ State Key Laboratory of Microbial Resources, CAS Key Laboratory of Microbial Physiological and Metabolic Engineering, Institute of Microbiology, Chinese Academy of Sciences, Beijing 100101, China

${ }^{e}$ University of Chinese Academy of Sciences, Beijing 100049, PR China

${ }^{f}$ Faculty of Life and Health Sciences, School of Biomedical Sciences, University of Ulster, Northern Ireland, UK

${ }^{g}$ The Key Laboratory of Marine Reservoir Evolution and Hydrocarbon Accumulation Mechanism, Ministry of Education, College of Energy Resources, China University of Geosciences (Beijing), Beijing 100083, China. E-mail: fanzhang123@126.com

$\dagger$ Electronic supplementary information (ESI) available. See DOI: 10.1039/d1ra07663a
Biosurfactant-producing microbes have been isolated from diverse settings including soil, oil reservoirs, seawater and marine sediments. Of these microbes, those originally derived from oil reservoirs have been found to be more readily adapted to use in similar oil reservoir settings. ${ }^{\mathbf{1 0}}$ Species of Bacillus, Acinetobacter, Rhodococcus, Enterobacter, Dietzia, Paenibacillus and Pseudomonas isolated from oil reservoirs have been found to produce a range of biosurfactants including lipopeptides, glycolipids, phospholipids and fatty acids. ${ }^{\mathbf{1 1 - 1 5}}$ Lipopeptides are generally amphiphilic compounds with excellent surface activity. Lipopeptides have been shown to be produced by species of Bacillus, Brevibacillus, Streptomyces, Arthrobacter and Pseudomonas. ${ }^{\mathbf{1 6 , 1 7}}$ Bacillus species including B.licheniformis, $B$. subtilis ${ }^{18}$ B. cereus, ${ }^{16}$ and B. amyloliquefaciens 19 have all been identified as major lipopeptide producers. As such, many Bacillus species have been studied to date in order to study the potential applications of their metabolites. ${ }^{\mathbf{2 0 , 2 1}}$ However, to date there has not been sufficient study of the properties of oil reservoir-derived Brevibacillus species or of their potential value in MEOR applications.

Biosurfactants are generally produced a mixture of congeners that can be readily extracted in crude forms. ${ }^{22}$ Purification or refining are usually not required for MEOR applications unlike the case when using in pharmaceuticals and cosmetics industries. ${ }^{23,24}$ The cost of using biosurfactant in enhancing oil recovery is often mainly the cost of their production. It is essential that fermentation conditions be optimized in order to increase the cost-effectiveness. ${ }^{25}$ Industrial waste represented 
a potential source of inexpensive substrate that can be used for biosurfactant production, ${ }^{\mathbf{2 6}}$ with studies having used residues composed of molasses, ${ }^{27}$ corn steep liquor, ${ }^{28}$ glycerol ${ }^{29}$ and cassava wastewater ${ }^{30}$ to successfully produce biosurfactant from a variety of microbes.

Factors affecting biosurfactant production from many microbes, and particularly from Bacillus, Pseudomonas and Candida species, has been a topic of intensive research. ${ }^{31,32}$ Few studies have sought to optimize biosurfactant production by Brevibacillus species. The lipopeptide production of a novel bacterial strain Brevibacillus sp. AVN 13 was optimized by using Box-Behnken design. ${ }^{33,34}$ The optimum conditions for bioemulsifier and exopolysaccharides production by thermophilic Brevibacillus borstelensis were obtained by different statistical optimization approaches. ${ }^{35}$ However, studies on the optimization of lipopeptide production by Brevibacillus borstelensis are scarce. Optimizing fermentation conditions can be challenging owing to the complexity of the fermentation environment. ${ }^{36}$ Response surface method (RSM) is a kind of chemometric method which have been frequently applied to the optimization of analytical methods, fermentation process, soil remediation method et al., because of their advantages such as a reduction in the number of experiments that need be executed resulting in lower reagent consumption and considerably less laboratory work. BoxBehnken design (BBD) is an approach of RSM wherein models are constructed and the simultaneous impact of multiple variables is assessed through a variety of statistical approaches in an effort to optimize appropriate experimental conditions. BBD approaches explore the relationships between several explanatory variables and one or more response variables, and such approaches have been used as an effective means of increasing biosurfactant production by optimizing culture conditions and media components in an efficient manner. ${ }^{37}$

At present, there are few reports focused on Brevibacillus borstelensis isolated from oil reservoirs based on MEOR. Bioemulsifier produced by Brevibacillus borstelensis were reported. ${ }^{35}$ However, studies on biosurfactant produced by Brevibacillus borstelensis were scarce. In the present study, we report the isolation and characterization of a novel biosurfactant producing $B$. borstelensis strain isolated from the CQ Oilfield in China. To reveal the characterization of biosurfactant produced by Brevibacillus borstelensis and its application in MEOR, column chromatography, gel chromatography and HPLC were used to separate and purify the biosurfactants produced by YZ-2. Composition of biosurfactants produced by YZ-2 was characterized via MALDI-TOF-MS/MS. We further utilize Box-Behnken design (BBD) in order to maximize biosurfactant production efficiency. The potential of YZ-2 for reducing interfacial tension was examined. Core flooding and micro-model tests were also conducted to further investigate the ability of microorganism toward MEOR process.

\section{Materials and methods}

\subsection{Microbe isolation and identification}

Oil and formation water were collected from oil wells of the CQ Oilfield in China which was located in Northwest China.
Individual $2 \mathrm{~mL}$ samples were then combined with $50 \mathrm{~mL}$ mineral enrichment medium (MEM; $7 \mathrm{~g} \mathrm{~L}^{-1} \mathrm{NH}_{4} \mathrm{NO}_{3}, 1 \mathrm{~g} \mathrm{~L}^{-1}$ $\mathrm{K}_{2} \mathrm{HPO}_{4}, 1 \mathrm{~g} \mathrm{~L} \mathrm{KH}_{2} \mathrm{PO}_{4}, 0.3 \mathrm{~g} \mathrm{~L}^{-1} \mathrm{MgSO}_{4}, 0.01 \mathrm{~g} \mathrm{~L}-1 \mathrm{Na}_{2} \mathrm{MoO}_{4}$, and $0.01 \mathrm{~g} \mathrm{~L}^{-1} \mathrm{FeSO}_{4}$; pH of 7.0-7.2), amended with $0.2 \mathrm{~g}$ sucrose and $2 \mathrm{~mL}$ crude oil collected from the same well. Samples were incubated at $35{ }^{\circ} \mathrm{C}$ for 72 hours with constant shaking at $150 \mathrm{rpm}$.

Next, $50 \mu \mathrm{L}$ culture supernatant samples were isolated and spread onto lysogeny broth (LB) agar plates, which were then incubated at $35{ }^{\circ} \mathrm{C}$ for 24 hours. The surface tension of the culture was determined using a surface tensiometer JK99B (Zhongchen Electronic Technology Co., Ltd., China). Those strains capable of decreasing surface tension were then selected and grown for 3 days at $35{ }^{\circ} \mathrm{C}$ in MEM supplemented with sucrose, with constant $150 \mathrm{rpm}$ shaking. The strain YZ-2 was chosen for further study as high yielding strain which reduced the surface tension of the culture up to $30.11 \pm 0.3 \mathrm{mN} \mathrm{m}^{-1}$ and produced biosurfactant with high emulsification activity of $E_{24}$ $=72 \% \pm 0.4 \%$.

Bergey's Manual of Systemic Bacteriology was referenced when assessing the YZ-2 stain in order to understand its morphology, physiology and phylogeny. In addition, the identification of the strain YZ-2 was followed the method described in previous reports. ${ }^{38}$

\subsection{Preparation of biosurfactant extracts produced by YZ-2}

A $5 \%(\mathrm{v} / \mathrm{v})$ inoculum of the YZ-2 strain in LB (optical density, $\mathrm{OD}_{600}=1$ ) was added to the fermentation medium (1 L: $20 \mathrm{~g}$ corn steep powder, $0.5 \mathrm{~g}$ yeast extract, $20 \mathrm{~g} \mathrm{NaNO}_{3}, 0.35 \mathrm{~g}$ $\mathrm{KH}_{2} \mathrm{PO}_{4}, 1.0 \mathrm{~g} \mathrm{Na}{ }_{2} \mathrm{HPO}_{4}, 0.25 \mathrm{~g} \mathrm{MgSO}_{4} \cdot 7 \mathrm{H}_{2} \mathrm{O}, 0.0075 \mathrm{~g} \mathrm{CaCl}$, $0.006 \mathrm{~g}, \mathrm{MnSO}_{4} \cdot \mathrm{H}_{2} \mathrm{O}, \mathrm{pH} 7.0$ ), followed by incubation at $35{ }^{\circ} \mathrm{C}$ for $96 \mathrm{~h}$ with constant shaking at $200 \mathrm{rpm}$. The broth was then centrifuged for 8 minutes at $10000 \mathrm{rpm}$, and the cell-free supernatant was collected. Next, $5 \mathrm{~mol} \mathrm{~L}^{-1} \mathrm{HCl}$ was used to adjust the supernatant $\mathrm{pH}$ to 2.0 , and the mixture was then stored for $10 \mathrm{~h}$ at $4{ }^{\circ} \mathrm{C}$ to precipitate the lipopeptides, after which solid crude lipopeptides were collected via spinning for 10 minutes at $10000 \mathrm{rpm}$ at $4{ }^{\circ} \mathrm{C}$. Crude lipopeptides was extracted with $30 \mathrm{~mL}$ methanol. The insoluble impurities were removed through filtration. A rotary evaporator was then used for methanol evaporation, yielding a crude biosurfactants extract. $^{39}$

\subsection{YZ-2 biosurfactant purification and structural analysis}

YZ-2 biosurfactant were dissolved using $\mathrm{CHCl}_{3}$ and loaded onto a silica gel column (100-200 meshes). Chloroform/methanol solvent $(5 / 0,4 / 1,3 / 2,1 / 4,0 / 5 ; \mathrm{v} / \mathrm{v})$ systems were used to wash the column in sequence to achieve biosurfactant recovery. ${ }^{40}$ The eluate being collected in $10 \mathrm{~mL}$ fractions. Each fraction was dried by rotary evaporation and dissolve in equal volume of deionized water. The Emulsification Index $\left(E_{24}\right)$ of each fraction was measured as described previously. ${ }^{41}$ The solution of each fraction was added with kerosene in a $1: 1$ ratio (v/v). The mixture solution was vortexed well and kept in an ambient condition for $24 \mathrm{~h}$. After incubation, the emulsifying index $\left(E_{24}\right)$ of each fraction was calculated by the following formula: 
$E_{24}=\frac{\text { emulsion height }}{\text { total height of the mixture solution }} \times 100 \%$.

The eluted fractions for which $E_{24}$ was $>50 \%$ were then combined and evaporated in a rotary at $50{ }^{\circ} \mathrm{C}$ in a vacuum to yield purified lipopeptides. These lipopeptides were then dissolved with methanol prior to loading onto a Daisogel-packed column for HPLC (SP-120-40/60-ODS-RPS, DAISO CO., Ltd, Japan). This column was washed with methanol/ $\mathrm{H}_{2} \mathrm{O}$ solvent systems $(5 / 0,4$ / $1,3 / 2,1 / 4,0 / 5 ; \mathrm{v} / \mathrm{v}$ ) in sequence to mediate biosurfactant recovery, with the eluate again being collected in $10 \mathrm{~mL}$ fractions and those fractions for which $E_{24}$ was $>50 \%$ being pooled to yield further purified lipopeptides. Finally, $0.8 \% \mathrm{NaCl}$ was used to dissolve these lipopeptides which were then loaded onto a Sephadex LH-20 column, with eluates again being pooled as above to yield a final preparation of purified lipopeptides.

\subsection{Biosurfactant evaluation}

Distilled water was used to prepare a range of concentrations of the purified lipopeptide $\left(0-100 \mathrm{mg} \mathrm{L}^{-1}\right)$. Changes in the surface tension in these samples were assessed, with the critical micelle concentration (CMC) being determined accordingly. In addition, the $E_{24}$ for these biosurfactants was determined as in previous reports. ${ }^{\mathbf{4 1}}$

The pendant drop apparatus was used for measuring the IFT followed by the method described in previous reports. ${ }^{42}$ The apparatus was designed in a way that it is possible to analyze the IFT by using an online image capturing system which enables us to record the data upon our desire periodically. In general, the analysis of IFT measurement is performed by injecting a drop from the needle with $2.05 \mathrm{~mm}$ diameter into a bulk phase under $30{ }^{\circ} \mathrm{C}$. The IFT between oil and different concentration of purified biosurfactant were measured.

The contact angle and interfacial tension were measured to investigate the ability of YZ-2 biosurfactant to alter the wettability of the rock surface. Interfacial tension between different concentration of biosurfactant solution and petroleum used in the micromodel test were measured at room temperature by using an interfacial tensiometer (KRUSS DSA30, Germany). A clean microscope glass slide was washed by chromic acid pickling solution and distilled water successively and was dried under $60^{\circ} \mathrm{C}$. After that, the microscope glass slide was aged in dewatered oil at $60{ }^{\circ} \mathrm{C}$ for about three weeks. The microscope glass slide was washed by toluene lightly to remove free oil on the glass surface. One of the glass slides was steeped in biosurfactant solution for one hour to allow the interaction between biosurfactant and glass surface. The contact angle of water and biosurfactant solution on the glass surface were measured by sessile drop method via a contact angle goniometer (KRUSS DSA30, Germany).

\subsection{Reverse-phase HPLC}

$\mathrm{CH}_{3} \mathrm{OH}$ was used to dissolve purified lipoproteins, which were then subjected to $0.22 \mu \mathrm{m}$ filtration. A $25 \mu \mathrm{L}$ volume of biosurfactant solution was then injected into an InterSustain C18 column $(5 \mu \mathrm{m}, 250 \mathrm{~mm} \times 4.6 \mathrm{~mm})$ in an HPLC system (Agilent 1260, USA) in order to separate out the lipopeptides within the crude preparation. The mobile phases were methanol (A) and water (B) containing $0.1 \%$ trifluoroacetic acid (TFA). Ultraviolet detector was used to detect lipopeptides in the eluent. The gradient strategy for this mobile phase system was as described in previous reports. ${ }^{43}$

\subsection{MALDI-TOF-MS}

A SCIEX 4800 Plus analyzer (Applied Biosystems, USA) with a $337 \mathrm{~nm}$ nitrogen laser for desorption and ionization was used for the assessment of HPLC-purified lipopeptides structures as previously described. ${ }^{\mathbf{4 3}}$

\subsection{Optimization of biosurfactant production}

A Box-Behnken design (BBD) approach was used to optimize the variables involved in the biosurfactant production. Based on previous studies, three input parameters were considered in the development of this optimized model: the concentrations of corn steep powder, $\mathrm{MgSO}_{4}$, and peptone in the fermentation broth.

The codes ranged for each of these three parameters were listed in Table 1. Three concentrations were tested for each of these three parameters, with these concentrations having been selected based upon preliminary experimental results. All other components of the fermentation medium were identical to that described in Section 2.2. Cultures were incubated for $96 \mathrm{~h}$ at $35{ }^{\circ} \mathrm{C}$ with constant shaking at $200 \mathrm{rpm}$. In total, 15 experimental groups were tested (Table 2), with biosurfactant yield being measured based on the weight of the crude biosurfactant preparations that were prepared as in Section 2.2.

The optimized values from BBD were determined by analyzing the results of this experiment. Analyses of variance (ANOVA) with 95\% confidence intervals (CIs) were used to gauge the significant of these effects, allowing for the identification of which conditions and interactions were necessary in order to achieve optimal biosurfactant production. ${ }^{44}$

\subsection{Core flooding}

The physical simulation experiments were performed to simulate the reservoir environment and to assess the ability of biosurfactants produced by YZ-2 to enhance oil recovery. Standard core flooding equipment was used as previously described. ${ }^{45}$ Core flooding equipment included a constant flow pump (Szweico 2PB, China), core holder, high pressure vessels, oven and confining pressure pump. The schematic of the experimental setup for the physical simulation experiment was shown

Table 1 Range of different factors invested in Box-Behnken experimental design

\begin{tabular}{lccc}
\hline & \multicolumn{2}{l}{ Range and levels } \\
\cline { 2 - 4 } Variables & -1 & 0 & 1 \\
\hline Corn steep liquor A $\left(\mathrm{g} \mathrm{L}^{-1}\right)$ & 20 & 35 & 50 \\
$\mathrm{MgSO}_{4}(\mathrm{~B})\left(\mathrm{g} \mathrm{L}^{-1}\right)$ & 0.2 & 0.35 & 0.5 \\
Peptone $(\mathrm{C})\left(\mathrm{g} \mathrm{L}^{-1}\right)$ & 1.2 & 1.8 & 2.4
\end{tabular}


Table 2 Box-Behnken experimental design for optimization of parameters for biosurfactant production

\begin{tabular}{|c|c|c|c|c|c|}
\hline Run & $\begin{array}{l}\text { Corn steep liquor } \\
\text { (A) }\end{array}$ & $\mathrm{MgSO}_{4}$ (B) & Peptone (C) & $\begin{array}{l}\text { Observed biosurfactant } \\
\text { yield }\left(\mathrm{g} \mathrm{L}^{-1}\right)\end{array}$ & $\begin{array}{l}\text { Predicted biosurfactant } \\
\text { yield }\left(\mathrm{g} \mathrm{L}^{-1}\right)\end{array}$ \\
\hline 1 & 0 & 1 & 1 & 2.51 & 2.44 \\
\hline 3 & -1 & -1 & 0 & 3.32 & 3.24 \\
\hline 4 & 0 & -1 & -1 & 2.70 & 2.77 \\
\hline 5 & 1 & 1 & 0 & 3.27 & 3.35 \\
\hline 8 & 0 & -1 & 1 & 3.36 & 3.33 \\
\hline 9 & 0 & 0 & 0 & 3.91 & 3.92 \\
\hline 10 & 1 & 0 & -1 & 3.43 & 3.33 \\
\hline 11 & 0 & 0 & 0 & 3.97 & 3.92 \\
\hline 12 & 1 & -1 & 0 & 3.66 & 3.69 \\
\hline 13 & 0 & 1 & -1 & 2.33 & 2.35 \\
\hline
\end{tabular}

in Fig. 1. The properties of oil and formation water were shown in Tables $\mathrm{S} 2$ and $\mathrm{S} 3 . \dagger$

The core samples used in the experiments were collected from Chang 6 reservoir of the CQ Oilfield in China. Cores were $7 \mathrm{~cm}$ long and $2.5 \mathrm{~cm}$ in diameter, with permeability values ranging from $42-47 \mathrm{mD}$ (Table $\mathrm{S} 1 \dagger$ ). They were cleaned with benzene and alcohol through Soxhlet apparatus and dried at $80{ }^{\circ} \mathrm{C}$ for 24 hours. The dry weight was measured. The dry core samples were evacuated for 2 hours and then saturated with formation water. The wet weight was measured. Pore volume (PV) and porosity were calculated based on the weight difference before and after the core was water saturated. The core samples were placed inside the core holder under a confining pressure of $1000 \mathrm{psi}$, and the initial liquid permeability was determined by flowing the formation water across the cores at a constant flow rate of $0.2 \mathrm{~mL} \mathrm{~min}^{-1}$. The dewatered and degassed oil were injected into the cores with a flow rate of 0.2 $\mathrm{mL} \min ^{-1}$ to establish initial oil saturation at $30{ }^{\circ} \mathrm{C}$ which was consistent with the reservoir temperature. After the saturation of water and oil, the core holder was kept at $30{ }^{\circ} \mathrm{C}$ for 3 days. Subsequently, cores were flooded with formation water until the water cut in the core effluent was $>98 \%$. Oil recovery was then calculated based upon the volume of recovered oil. ${ }^{46}$
After secondary injection, cores D, A, B and E were injected with $1 \mathrm{PV}$ of $60 \mathrm{mg} \mathrm{L}^{-1}, 90 \mathrm{mg} \mathrm{L}^{-1}, 120 \mathrm{mg} \mathrm{L}^{-1}$ and $150 \mathrm{mg} \mathrm{L}^{-1}$ biosurfactant solution, respectively. As a control, core $\mathrm{C}$ was injected with $1 \mathrm{PV}$ of formation water and incubating for 2 hours. Then, the subsequent water flooding was conducted. The water injection was stopped when water cut reached $98 \%$. The accumulative oil production was recorded. The biosurfactant and subsequent water flooding recovery was calculated as above. $^{12}$

\subsection{Micromodel test}

The oil used in this test was the same as in the Section 2.8. The manufacturing process of the micromodels has been described by Dunsmore. ${ }^{47}$ Briefly, a micromodel consisted of two glass plates, one with an interconnected, acid-etched network being annealed to the other, un-etched plate. The inner radius of the core channels was approximately $50 \mu \mathrm{m}$ (ESI Fig. S1†). A schematic diagram of the micromodel apparatus was followed by Dong. ${ }^{12}$ The basic elements of the apparatus are the pumping system and the associated flow lines, the micromodel in its holder, the photography system, and the monitoring computer system. Micromodels were first saturated with crude oil at $60{ }^{\circ} \mathrm{C}$
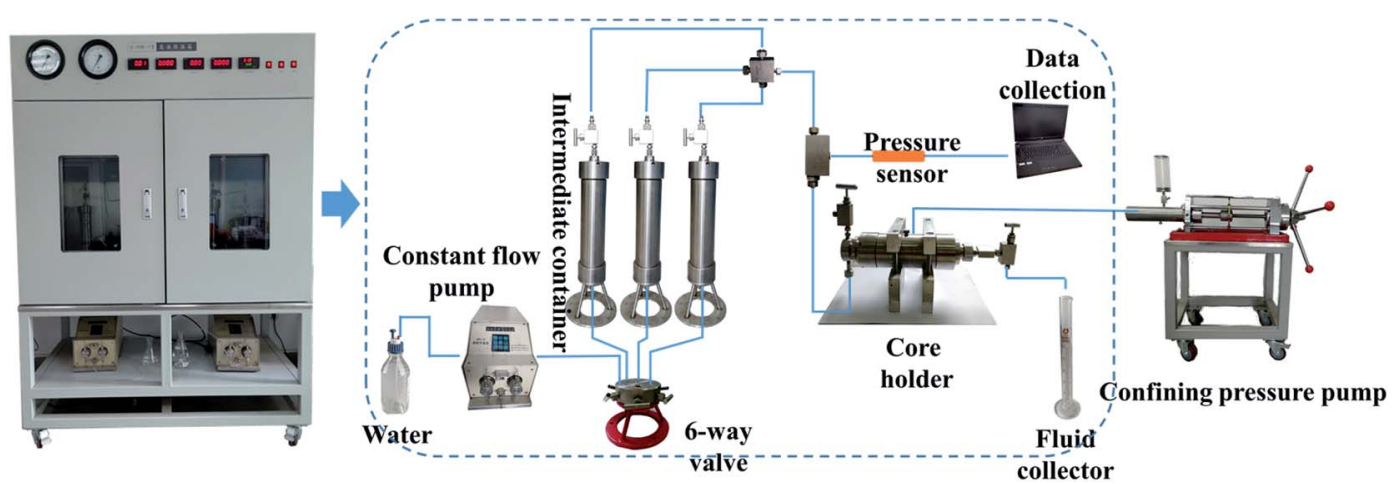

Fig. 1 Schematic of the core displacement experiment set up. 
for 3 weeks. Then, formation water was injected into the micromodels to simulate the first water flooding. The flow rate of the flooding water was controlled at $1 \mu \mathrm{L} \min ^{-1}$ with a constant flow pump (LongerPump TS-1B, China). The pump and micromodels were connected with Masterflex 06409-13 tygon tubing (Saint-Gobain, France). The temperature of the flow system and micromodel was maintained at $30{ }^{\circ} \mathrm{C}$ via a micro warm plate (Kitazato, Japan). Subsequently, cell free fermentation broth containing biosurfactants was injected into model for $20 \mathrm{~min}$, followed by second water flooding. Photographs were taken during the flooding period every 2 min with an EOS550D digital single lens reflex camera (Canon, Inc., Japan).

\section{Results and discussion}

\subsection{Isolation of a biosurfactant-producing microbe}

We selected the strain YZ-2 isolated from oil well production water for further study owing to its ability to emulsify oil and to effectively reduce ST. Strain YZ-2 was a motile Gram-positive microbe that grew well in temperatures from $20-60{ }^{\circ} \mathrm{C}, \mathrm{pH}$ values from $4-11$, and salinity values from $0 \%-20 \%$. We were able to obtain a nearly complete YZ-2 16S rRNA gene sequence (1382 bp), and a phylogenetic analysis (Fig. 2) revealed it to have 99\% sequence similarity to that of Brevibacillus borstelensis. Brevibacillus species have been isolated from petroleum reservoirs, petroleum contaminated soil. Phenanthrene-degrading bacterial strain Brevibacillus sp. PDM-3 which was isolated from hydrocarbon contaminated sludge samples has the ability to produce glycolipid-biosurfactant during phenanthrene degradation. ${ }^{48}$ Brevibacillus brevis HOB1 was isolated from the formation water of an oil field and found to produce lipopeptides and have the ability to enhance oil recovery. ${ }^{49}$ Brevibacillus originally derived from petroleum reservoir showed potential application in microbial oil recovery.

\subsection{The production and characterization of biosurfactants produced by Brevibacillus borstelensis YZ-2}

After a $72 \mathrm{~h}$ fermentation, biosurfactants were extracted from the broth and lyophilized. These purified biosurfactants were able to reduce the $\mathrm{ST}$ of water from $72 \pm 0.2 \mathrm{mN} \mathrm{m}^{-1}$ to $30.11 \pm$ $0.3 \mathrm{mN} \mathrm{m}^{-1}$ at room temperature when added at a $60 \mathrm{mg} \mathrm{L}^{-1}$ concentration. We further characterized the oil spreading, kerosene emulsification, and variation of surface tension versus concentration for purified biosurfactant (Fig. 3a-c). The CMC value for this biosurfactant preparation was estimated to be $\sim 60 \mathrm{mg} \mathrm{L}^{-1}$, with a minimum ST value of $30.11 \pm 0.3 \mathrm{mN} \mathrm{m}^{-1}$. The purified biosurfactants were able to reduce the water-oil interfacial tension from $18.51 \pm 0.1 \mathrm{mN} \mathrm{m}^{-1}$ to $1.32 \pm 0.09 \mathrm{mN}$ $\mathrm{m}^{-1}$ at room temperature when added at a $60 \mathrm{mg} \mathrm{L}^{-1}$ concentration. Poulami Datta et al. compared the oil washing efficiencies of lipopeptides, trehalose lipids and rhamnolipids produced by different strains. The CMC, surface tension and interfacial tension were ranged from $20-250 \mathrm{mg} \mathrm{L}{ }^{-1}, 25-38.4$ $\mathrm{mN} \mathrm{m}^{-1}$ and $0.32-11.3 \mathrm{mN} \mathrm{m}^{-1}$, respectively. These results showed the excellent interfacial active of biosurfactant produced by $\mathrm{YZ}-2 .{ }^{50}$

\subsection{Structural characterization}

We next used reverse-phase HPLC to characterize these purified biosurfactants produced by strain YZ-2, with all active fractions in the resultant chromatogram being analyzed (Fig. 4a). Retention times ranged from 2-6 $\mathrm{min}, 10-30 \mathrm{~min}$ and 32$35 \mathrm{~min}$. The rapidly eluted fraction was ultimately determined to contain homologs with shorter fatty acid chains and pigments. ${ }^{18}$ These separated HPLC fractions were then assessed for their ability to modulate surface activity via a surface tension meter, with the surface-active fractions that were eluted at 23.12 minute being collected and analyzed via MAIDI-TOF-MS.

The MS under positive ions mode revealed that the $\mathrm{m} / \mathrm{z}$ of the purified lipopeptides were ranged from 1421.8 to 1566.8 . The

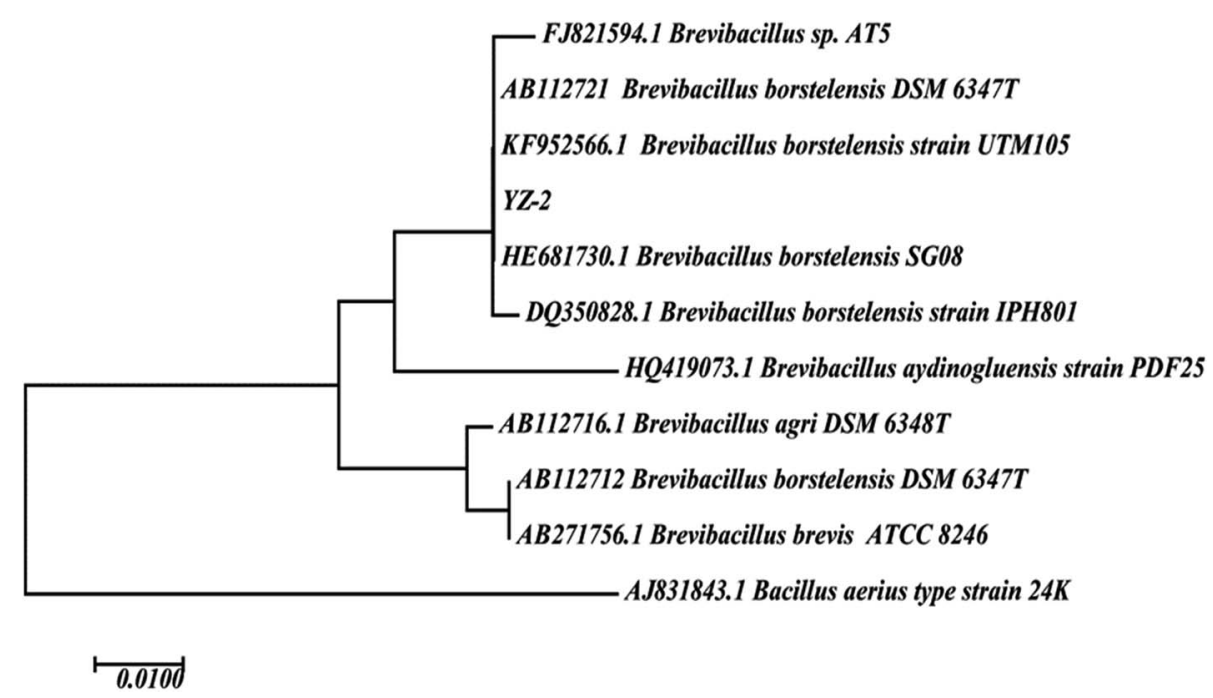

Fig. 2 Phylogenetic relationship based on the 16S rDNA gene sequences between strain YZ-2 and species in the Pseudomonas as determined by the neighbor-joining algorithm and evaluated by the maximum-likelihood and maximum parsimony algorithms. 


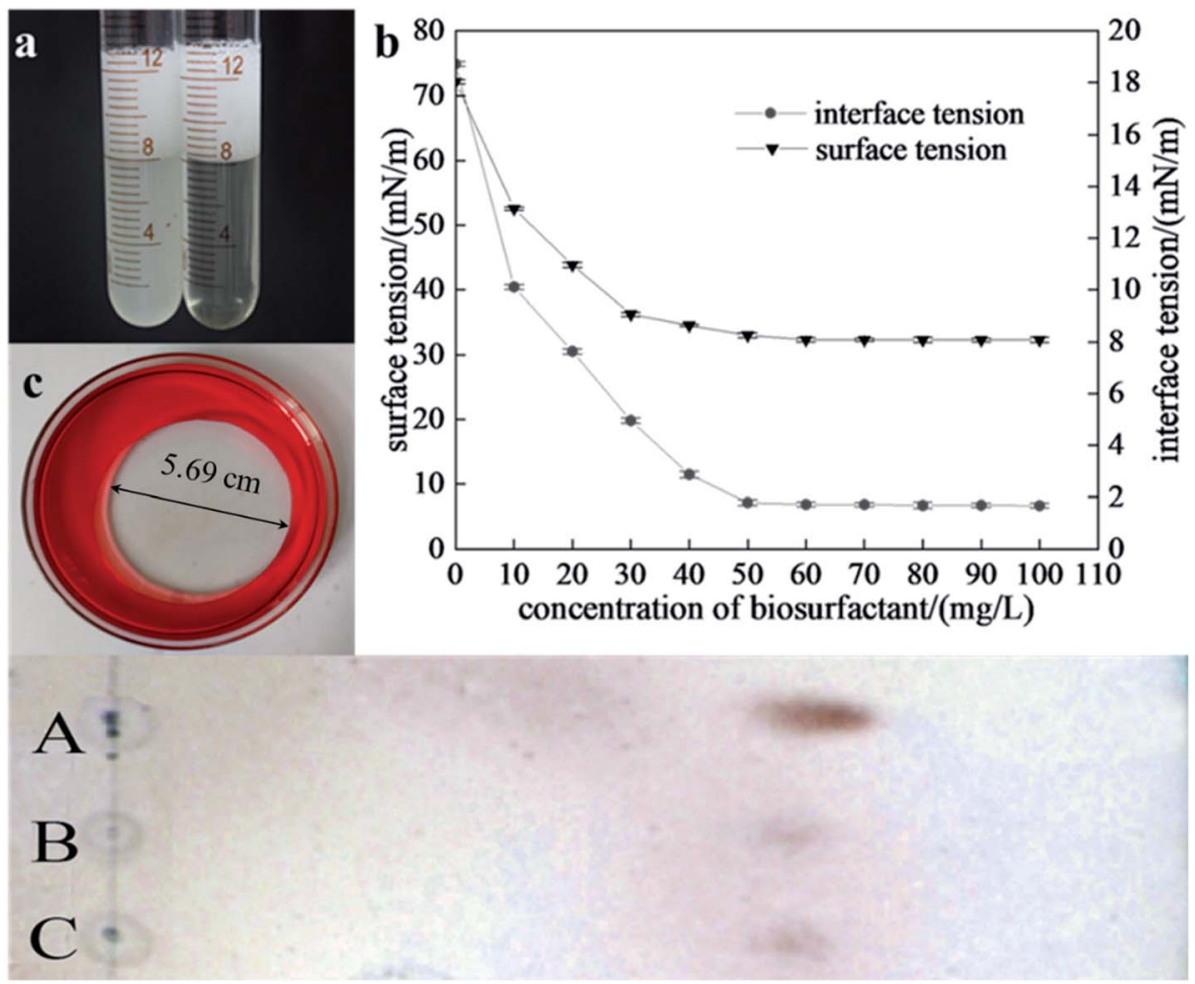

Fig. 3 Characteristic of biosurfactant produced by strain YZ-2. (a) Showed the kerosene emulsification caused by biosurfactant produced by strain; (b) showed oil spreading of biosurfactant produced by strain YZ-2. (c) Showed the surface tension and water-oil interfacial tension of different concentration of biosurfactant.

main ions at $\mathrm{m} / \mathrm{z} 1485.72,1499.76,1513.78$ and 1527.8 , there were $14 \mathrm{Da}$ difference between each other. This suggests they were homologues with different number of $\mathrm{CH}_{2}$. Peaks with $\mathrm{m} / \mathrm{z}$ of $1477.77,1491.79,1515.8$ and 1529.79 also represent they were homologues with different number of $\mathrm{CH}_{2}$. Molecular ions which yield mass decrease of 2 Da suggest the presence of unsaturated fatty acids, such as peaks with $\mathrm{m} / \mathrm{z}$ of 1513.78 and 1515.8, 1527.8 and 1529.79. Peaks with $\mathrm{m} / \mathrm{z}$ of $1477.77,1499.76$, 1515.8, were considered to be protonated ions $[\mathrm{M}+\mathrm{H}]^{+}$, sodium adductions $[\mathrm{M}+\mathrm{Na}]+$ and potassium adductions $[\mathrm{M}+\mathrm{K}]^{+}$of a component with a molecular weight of 1476.77 , respectively. ${ }^{31}$ Peaks with $\mathrm{m} / \mathrm{z}$ of $1491.79,1513.78$ and 1529.79 were considered to be protonated ions, sodium adductions and potassium adductions of a component with a molecular weight of 1490.8, which we believe to be a homolog of the component with a molecular weight of 1476.77 . These $\mathrm{m} / \mathrm{z}$ of the main peaks were the same to the reported fengycins and its homologs. ${ }^{51,52}$

The fragment ions of purified biosurfactants were analyzed via MALDI-TOF-MS/MS to classify compounds. Two classes of fengycins, fengycin A has DAla at position 6 and fengycin B has DVal at position 6 have been reported so far. Fragment ions produced by the cleavage of Glu1-Orn2 and Orn2-Tyr3 have been used as fingerprint ions to identify fengycins and its homologs (Fig. S1†). Three fingerprint ions y8, y9 and b1 which reported by Pathak (2012) were used here. ${ }^{51}$ y8 and y9 fingerprint ions are produced by the leaves of "fatty acid chain-Glu" and "fatty acid chain-Glu-Orn" from the $\mathrm{N}$ terminus.
Fingerprint ions couple y8/y9 were used to identify fengycin homologues. b1 fingerprint ion was used to identify the nature and length of a fatty acid part. Peak with $\mathrm{m} / \mathrm{z}$ of 1499.76 was considered to be sodium adductions $[\mathrm{M}+\mathrm{Na}]^{+}$of a component with a molecular weight of 1476.77. Fingerprint ion couple (994.07/1108.7) were obtained by the cleavage of molecular ions $\mathrm{MH}^{+}$at $m / z 1499$ (Fig. 4c), this pair of ions were obtained from fengycin B as previous report. ${ }^{51,52}$ This confirmed that the fengycin at $m / z 1476$ was fengycin B containing a C16 lipid chain. Fengycin were reported as a kind of cyclic lipopeptides which were generated by the member of Bacillus sp., such as Bacillus mojavensis, Bacillus subtilis, Bacillus amyloliquefaciens. It shows strong antifungal activity and can inhibits the growth of variety of plant pathogens. ${ }^{53}$ However, reports about fengycin produced by microorganisms isolated from petroleum reservoir and its application in petroleum exploitation are scarce. In this research, we isolated a strain Brevibacillus borstelensis YZ-2 which can produce fengycins and show its potential in petroleum exploitation. The fengycin of lipopeptides is a well-known anti-fungal substance. Moreover, it evidences excellent interfacial activity as a lipopeptide biosurfactant. Fengycin A, B and S produced by Bacillus amyloliquefaciens LSC04 were compared with biosurfactant produced by Nocordia sp. L-417 and several commercial surfactants. The results showed that the emulsification activities of the biosurfactants produced by LSC04 were superior to these surfactants except with tween detergents; 

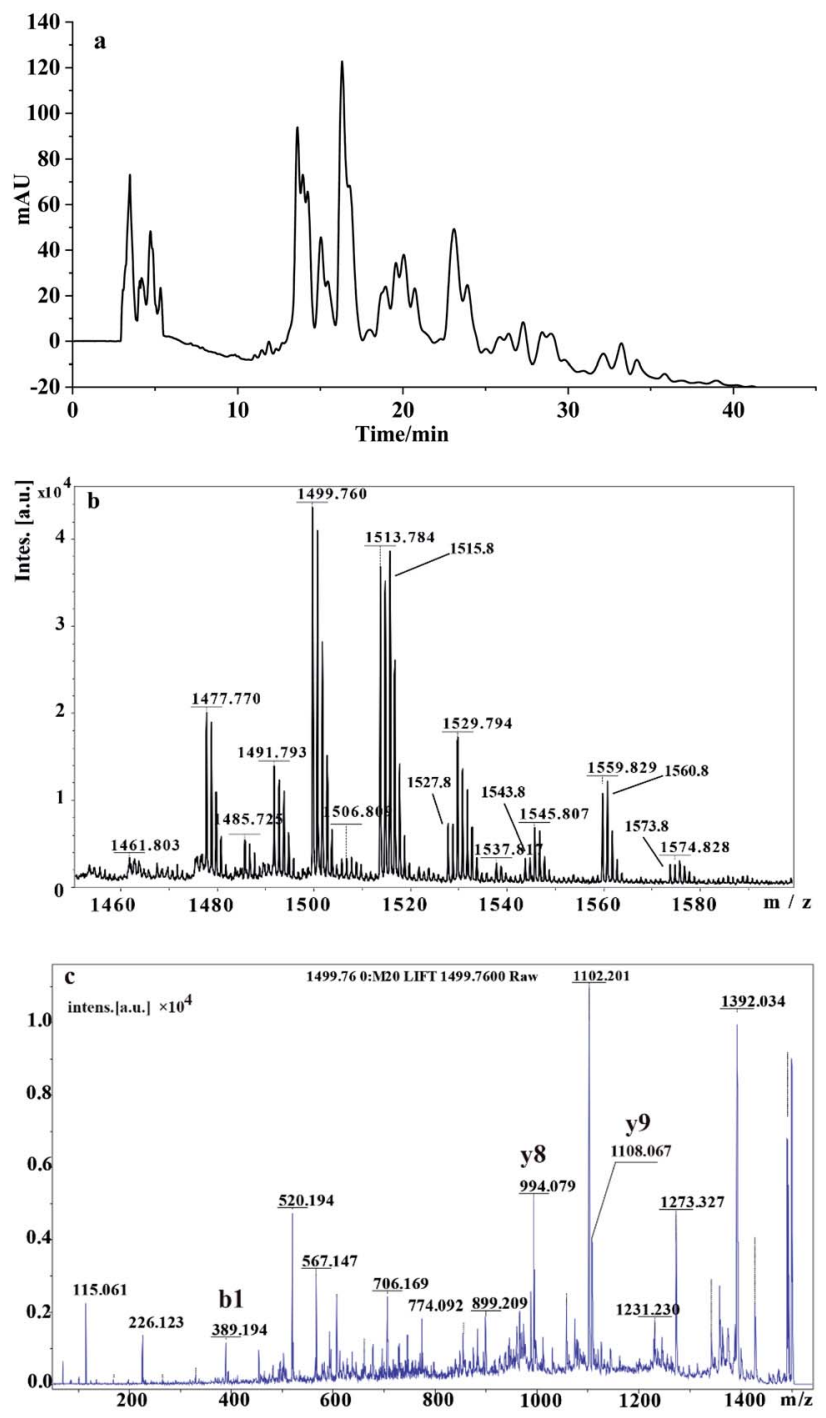

Fig. 4 Structural analysis of biosurfactants produced by Brevibacillus borstelensis YZ-2. (a) Showed RP-HPLC chromatograms of purified biosurfactants produced by Brevibacillus borstelensis YZ-2, (b) showed mass spectra of the HPLC fractions eluting at 23.12 min of the biosurfactants produced by $Y Z-2$. (c) Showed MS/MS spectra ions $\mathrm{m} / \mathrm{z}$ 1499.76.

however, its emulsification stability was far superior to that of the surfactants tested. ${ }^{19,53}$

\subsection{Optimization of biosurfactant production}

The interaction of component of the medium on biosurfactants production was shown in Table 3. A two second-order polynomial equation (eqn (1)) was generated by the results shown in Table 3. The relationship between the controllable variables and the responses can be numerically explained by the second-order polynomial equation. This polynomial equation made a correlation between the concentration of corn steep powder, $\mathrm{MgSO}_{4}$ and peptone in the fermentation broth, were designed as A, B and $\mathrm{C}$, respectively, with biosurfactants yield. The concentration of corn steep powder, $\mathrm{MgSO}_{4}$, and peptone were chosen as critical variables for the biosurfactant production to increase the yield of biosurfactant.

$$
\begin{gathered}
\text { Biosurfactant yield }=2.92+0.38 \mathrm{~A}-0.33 \mathrm{~B}+0.16 \mathrm{C}+0.15 \mathrm{AB} \\
-0.29 \mathrm{AC}-0.12 \mathrm{BC}-0.34 \mathrm{~A}^{2}-0.44 \mathrm{~B}^{2}-0.76 \mathrm{C}^{2}
\end{gathered}
$$

The statistical significance and fitness of this polynomial equations was analyzed through ANOVA (Table 3 ). The results of Fisher's $F$-test for the quadratic model were significant $(P<$ $0.05)$. This study also had a strong correlation coefficient $\left(R^{2}\right)$ of 0.9911, consistent with a strong correlation between observed experimental values and model predicted values. We can perform a mathematical analysis of the quadratic model as showed in eqn (1). The most significant factors influence on the biosurfactant production was $\mathrm{A}$, corresponding to the corn steep powder concentration, with a regression coefficient $\beta_{\mathrm{A}}=$ 0.38 , followed by concentration of $\mathrm{MgSO}_{4}$, with a regression coefficient $\beta_{\mathrm{B}}=-0.33$. Peptone concentration had smaller influence on biosurfactant yield than corn steep powder and $\mathrm{MgSO}_{4}$. This was reflected in the regression coefficient of peptone concentration in eqn (1). The quadratic terms of corn steep powder, $\mathrm{MgSO}_{4}$ and peptone were adjusted to a curve line with the different values of the slope. $\mathrm{C}^{2}$ is in the first position of the polynomial equation with a value $\beta_{\mathrm{CC}}=-0.76$, followed by $\beta_{\mathrm{CC}}=-0.44$ and $\beta_{\mathrm{AA}}=-0.34$. According to the coefficients of the interaction terms, the influence of corn steep powder concentration on biosurfactant yield depends greatly on the concentration of peptone and to a lesser extent on $\mathrm{MgSO}_{4}$ concentration; the terms $\mathrm{AB}$ and $\mathrm{AC}$ appear in sixth and seventh place of the polynomial equation, respectively, with regression coefficients $\beta_{\mathrm{AB}}=-0.29$ and $\beta_{\mathrm{AC}}=0.15$. Based on the polynomial equation, the numerical optimization of this model was conducted using the goal parameter "in range" and a response goal of "maximize", yielding predicted optimal parameter values of $42.09 \mathrm{~g} \mathrm{~L}^{-1}$ corn steep powder, $0.31 \mathrm{~g} \mathrm{~L}^{-1} \mathrm{MgSO}_{4}$, and $1.82 \mathrm{~g} \mathrm{~L}^{-1}$ peptone. This combination yielded $3.78 \pm 0.22 \mathrm{~g} \mathrm{~L}^{-1}$ of biosurfactant, which was similar to the predicted yield of $4.06 \mathrm{~g} \mathrm{~L}^{-1}$.

We additionally generated $3 \mathrm{D}$ response surface plots highlighting the mutual interactions between these three parameters and their influence on biosurfactant yields (Fig. 5A-C). Each plot indicates the interaction between two parameters and the associated impact on biosurfactant yield when the third parameter is fixed. Elliptical contour plots indicated mutual interactions between these parameters, whereas circular plots correspond negligible or interactions. The plots in Fig. 5A-C correspond to the effect of interactions between corn steep powder and $\mathrm{MgSO}_{4}$, corn steep powder and peptone, $\mathrm{MgSO}_{4}$ and peptone effects on biosurfactant yields, with fixed peptone, $\mathrm{MgSO}_{4}$, and corn steep powder concentrations of $1.80 \mathrm{~g} \mathrm{~L}^{-1}$, $0.35 \mathrm{~g} \mathrm{~L}^{-1}$ and $30 \mathrm{~g} \mathrm{~L}^{-1}$, respectively. Fig. 5 clearly demonstrated that biosurfactant yields increased as concentrations of corn steep powder, $\mathrm{MgSO}_{4}$ and peptone rose to middling levels, before falling when these values rose above a particular level. As the contour plots in Fig. 5A and $\mathrm{B}$ are elliptical, this indicated that there were significant interactions between factors A, B and 
Table 3 Analysis of variance results for the quadratic model for optimization of biosurfactant production

\begin{tabular}{|c|c|c|c|c|c|c|}
\hline Source & Sum of squares & $\mathrm{d} f$ & Mean square & $F$ value & $P$-value & Prob $>F$ \\
\hline Model & 5.61 & 9 & 0.62 & 61.54 & 0.0001 & Significant \\
\hline A-corn steep liquor & 1.16 & 1 & 1.16 & 114.73 & 0.0001 & \\
\hline $\mathrm{B}-\mathrm{MgSO}_{4}$ & 0.86 & 1 & 0.84 & 84.66 & 0.0003 & \\
\hline C-peptone & 0.21 & 1 & 0.21 & 21.17 & 0.0059 & \\
\hline $\mathrm{AB}$ & 0.096 & 1 & 0.096 & 9.48 & 0.0275 & \\
\hline $\mathrm{AC}$ & 0.33 & 1 & 0.33 & 32.62 & 0.0023 & \\
\hline $\mathrm{BC}$ & 0.057 & 1 & 0.057 & 5.68 & 0.0629 & \\
\hline$A^{2}$ & 0.43 & 1 & 0.43 & 42.42 & 0.0013 & \\
\hline $\mathrm{B}^{2}$ & 0.71 & 1 & 0.71 & 70.13 & 0.0004 & \\
\hline $\mathrm{C}^{2}$ & 2.11 & 1 & 2.11 & 208.36 & $<0.0001$ & \\
\hline Residual & 0.051 & 5 & 0.010 & & & \\
\hline Lack of fit & 0.047 & 3 & 0.016 & 7.38 & 0.1217 & Not significant \\
\hline Pure error & $4.2 \times 10^{-3}$ & 2 & $2.100 \times 10^{-3}$ & & & \\
\hline Cor total & 5.66 & 14 & & & & \\
\hline Std. Dev. & 0.10 & $R$-squared & 0.99 & & & \\
\hline Mean & 3.10 & Adj $R$-squared & 0.97 & & & \\
\hline C.V.\% & 3.26 & Pred $R$-squared & 0.87 & & & \\
\hline Press & 0.76 & Adeq precision & 23.48 & & & \\
\hline
\end{tabular}

between factors B, C. Modifying just one of these factors is not a reliable means of predicting biosurfactant properties. The contour plot in Fig. 5C indicates that there is a weak interaction between factors $\mathrm{B}$ and $\mathrm{C}$, thus suggesting that varying either of these factors can be used as a means of predicting the properties of the resultant biosurfactant solution. The cost of raw materials is the major cost in most of biotechnological processes, ${ }^{54}$ especially in MEOR process. Industrial by-product, such as molasses, corn steep liquor and waste cooking oil were used to enhance the yield of biosurfactant and reduce the cost of biosurfactant production. ${ }^{27,28}$ In this study, the improvement of biosurfactant production by $29.5 \pm 0.6 \%$ suggested the BoxBehnken design in this work is successful. Corn steep liquor is the most influential factor according to our results. This suggested corn steep liquor as a suitable low-cost substrate for the production of biosurfactant. It is clear that the use of corn steep liquor as sole raw material is expected to reduce the overall production cost of biosurfactant.

\subsection{Core flooding test}

In order to simulate the MEOR process, we conducted a core flooding test that incorporated five test groups in order to examine the ability of YZ-2-derived biosurfactants to enhance oil recovery (Fig. 6). In core $\mathrm{C}$, which was a control core, secondary injection mediated $32.6 \%$ original oil in place (OOIP) recovery owing to its volumetric sweep efficiency, with a tertiary injection recovering an additional $2.7 \%$ of OOIP. In core A, B, D and $\mathrm{E}, 33.6 \%, 33.8 \%, 32.6 \%$ and $34.2 \%$ OOIP recovery was achieved upon secondary injection, respectively. Then 1 PV of different concentration $\left(60 \mathrm{mg} \mathrm{L}^{-1}, 90 \mathrm{mg} \mathrm{L}^{-1}, 120 \mathrm{mg} \mathrm{L}^{-1}\right.$, $150 \mathrm{mg} \mathrm{L}^{-1}$ ) of biosurfactant solution were injected into core A, $\mathrm{B}, \mathrm{D}$ and $\mathrm{E}$, respectively; additional 3.4\%, 6.4\%, $11.7 \%$ and $11.8 \%$ of OOIP was recovered upon the tertiary injection. The results showed that the biosurfactant were able to enhance the oil recovery after water flooding. Biosurfactant produced by YZ-2 can reduce oil-water interfacial tension from $18.51 \pm 0.1 \mathrm{mN}$ $\mathrm{m}^{-1}$ to $1.32 \pm 0.09 \mathrm{mN} \mathrm{m}^{-1}$. IFT reduction was consider to be important mechanism in biosurfactant enhanced oil recovery. ${ }^{55,56}$ When the biosurfactant solution contact the trapped crude oil in the porous medium, it obviously reduces the oil-water IFT and mobilizes the trapped crude oil by reducing capillary tension. The reduction of oil-water IFT caused by different concentration (60 $\mathrm{mg} \mathrm{L}^{-1}, 90 \mathrm{mg} \mathrm{L}^{-1}, 120 \mathrm{mg} \mathrm{L}^{-1}$ and $150 \mathrm{mg} \mathrm{L}^{-1}$ ) of YZ-2 biosurfactant was similar. However, higher oil recovery was obtained by injecting higher concentration of biosurfactant solution. The loss of surfactant during the surfactant flooding was reported. ${ }^{57}$ Core flooding test showed that higher concentration of biosurfactant than CMC was needed to achieve more oil displacement.

\subsection{Micromodel experiments}

The micromodel test showed that the residual oil in the model after water flooding mainly exists in the following forms: (1) columnar residual oil (Fig. 7a); (2) flaky residual oil (Fig. 7c); (3) film residual oil (Fig. 7e). A large amount of film residual oil indicated that the active component in the petroleum was closely adsorbed on the pore wall. This showed that the pore wall had become oil wet in the previous oil aging process. It showed that oil-water interfacial tension was reduced from $18.51 \pm 0.1 \mathrm{mN} \mathrm{m}^{-1}$ to $1.32 \pm 0.09 \mathrm{mN} \mathrm{m}^{-1}$ by the biosurfactant solution $\left(60 \mathrm{mg} \mathrm{L}^{-1}\right)$. The contact angle of water on the oil aged glass slides surface was $97.7 \pm 0.3^{\circ}$ while contact angle of biosurfactant solution $\left(60 \mathrm{mg} \mathrm{L}^{-1}\right)$ was $10.4 \pm 0.2^{\circ}$ (Fig. S2 $\dagger$ ). The reservoir pores were supposed to be capillaries, the radius of which is equal to the pore radius $50 \mu \mathrm{m}$. Capillary force is the main resistance during water flooding. The capillary force can be calculated by eqn (2).

$$
P_{\mathrm{c}}=\frac{2 \delta}{\gamma} \cos \theta
$$

$P_{\mathrm{c}}$ : capillary force; $\delta$ : interfacial tension between water and oil; $\gamma$ : capillary radius; $\theta$ : contact angle between water and oil. 

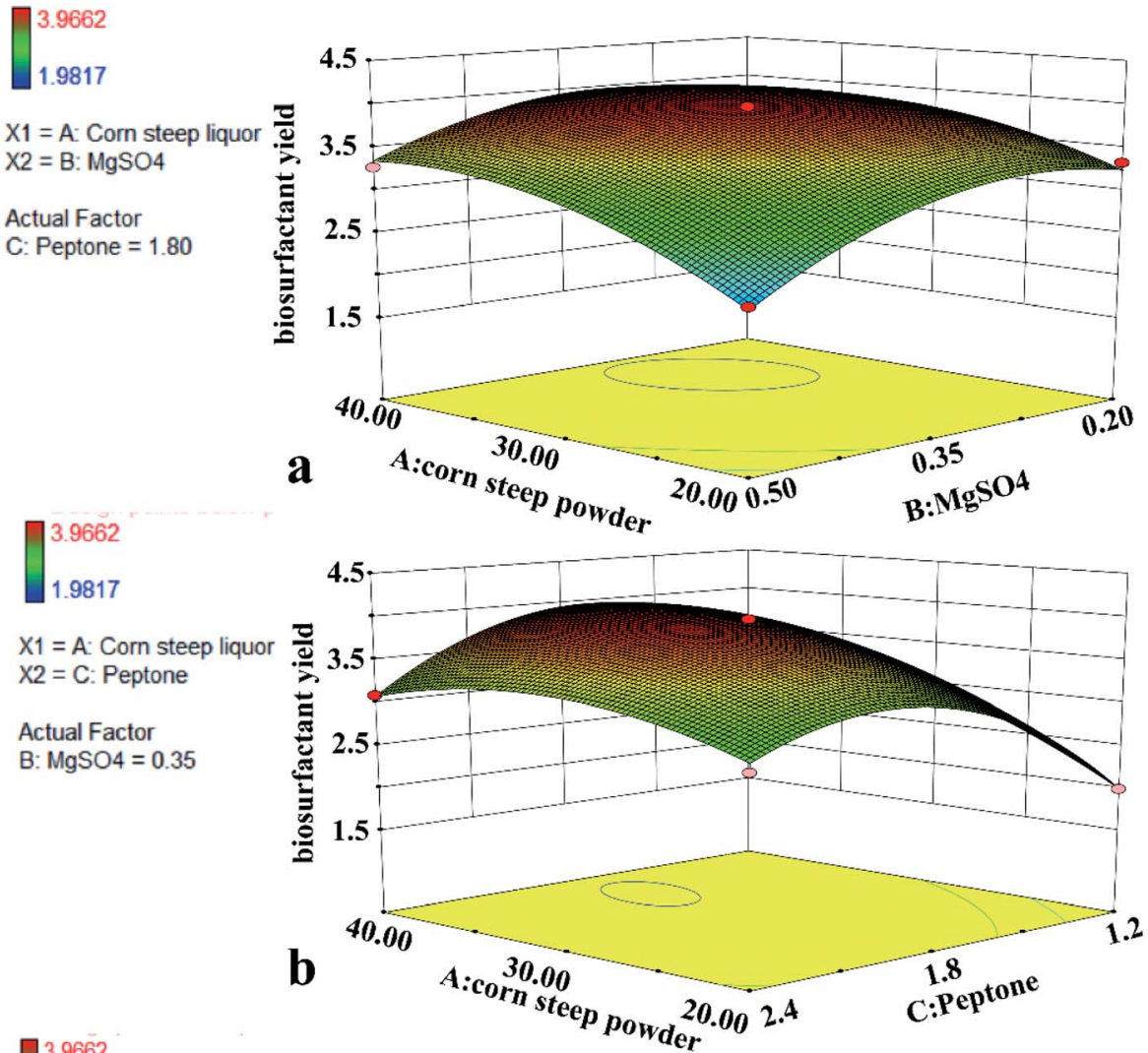

\subsection{7}

$\mathrm{X} 1=\mathrm{B}: \mathrm{MgSO} 4$ X2 = C: Peptone

Actual Factor A: Corn steep liquor $=30.00$

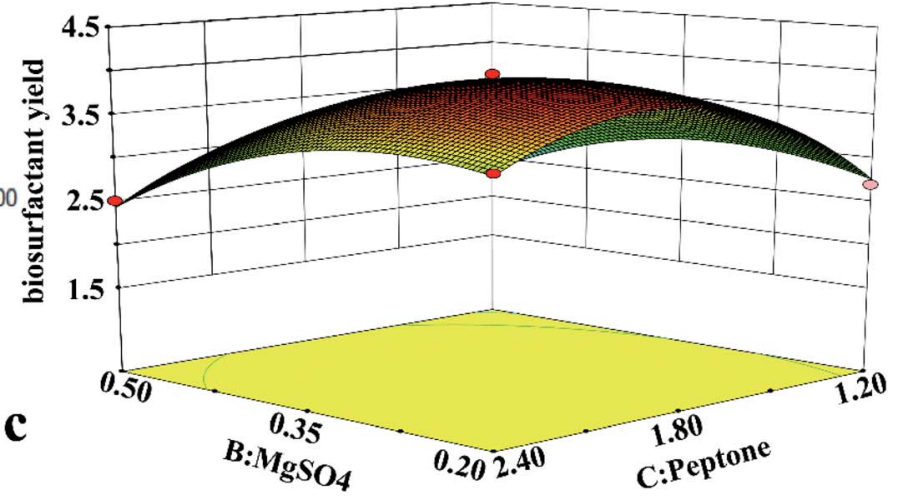

Fig. 5 Response surface plots and contour plots for maximum biosurfactant yield generated using data in Table 3 . Inputs, 15 experimental runs carried out under conditions established by BBD; production of biosurfactant as function of (a) corn steep powder and $\mathrm{MgSO}_{4}$; (b) corn steep powder and peptone; (c) $\mathrm{MgSO}_{4}$ and peptone.

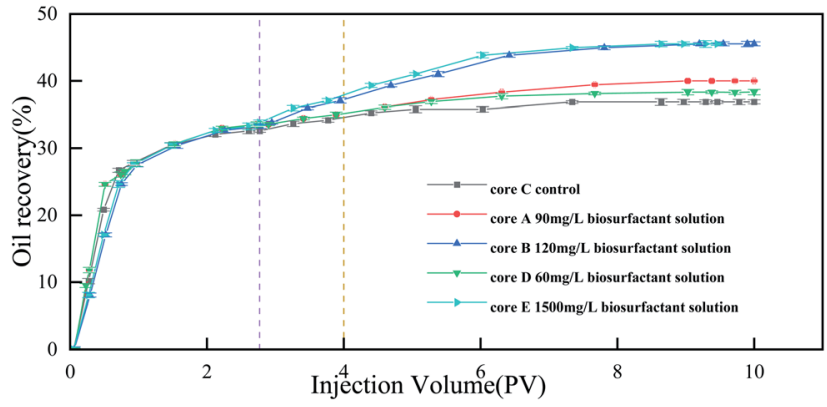

Fig. 6 Change of oil recovery versus injected PV in core model.
According to eqn (2), the capillary force of water in the pores was $-9.9 \times 10^{4} \mathrm{mN} \mathrm{m}^{-2}$. The negative sign of capillary force indicated that the direction of capillary force was opposite to water flooding. Capillary force was the resistance of water flooding. During the biosurfactant flooding process, the capillary force of biosurfactant solution in the pores was $5.2 \times 10^{4}$ $\mathrm{mN} \mathrm{m}{ }^{-2}$. The direction of capillary force was consistent with that of biosurfactant flooding. Capillary force was the driving force of oil displacement. The change of capillary force made it easier for surfactant solution to enter the capillary with smaller radius and improve sweep coefficient. Columnar residual oil in the pore was difficult to drive out because the capillary 


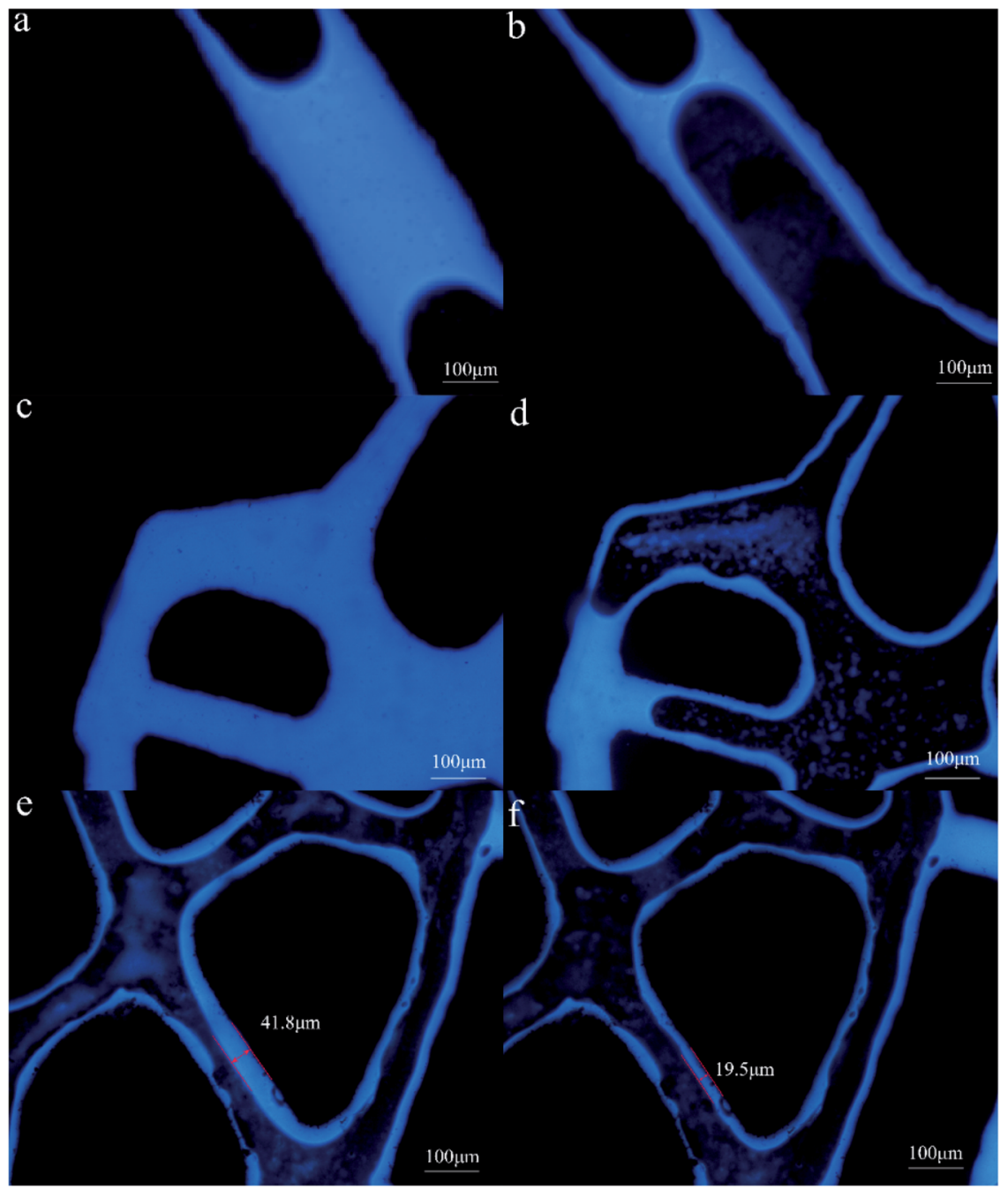

Fig. 7 Fluid distribution after water flooding and biosurfactant flooding. Blue: oil, black: solid, colorless transparent (black in pore): water phase.

resistance was formed at the oil column (Fig. 7a). The subsequent process of displacing the residual oil of the oil column with surfactant was showed in Fig. 7b. On one hand, YZ-2 biosurfactant changed the capillary force from oil displacement resistance to oil displacement power. On the other hand, crude oil was stripped from large oil column, emulsified into small particles and dispersed in the displacement fluid. In this process, the length of oil column decreased continuously until it was completely opened up and finally driven out with surfactant solution. Some of the oil was adsorbed on the pipe wall in the form of film residual oil, which was difficult to drive out. The oil recovery mechanism of flaky residual oil in the pores was similar to the columnar residual oil. In the process of water flooding, the formation water was difficult to sweep and drive out the flaky residual oil in the pore (Fig. 7c). In the process of surfactant flooding, the sweep volume increased and the crude oil was stripped off through emulsification and flows out of the pore with the surfactant solution (Fig. 7d). Oil film residual oil accounts for a large proportion of residual oil. It was shown in Fig. 7e, the thickest part of the oil film was $41.8 \mu \mathrm{m}$ after water flooding. In the process of surfactant displacement, the crude oil attached to the rock surface was dispersed and stripped under the condition of shear force. The $\mathrm{O} / \mathrm{W}$ emulsion was produced with injected water and the thickness of the oil film reduced from $41.8 \mu \mathrm{m}$ to $19.5 \mu \mathrm{m}$ (Fig. 7f) which decreased by $53.3 \%$.

The findings and mechanisms of surfactant flooding are summarized to be IFT reduction, wettability alteration and emulsification of petroleum. ${ }^{58,59}$ The MEOR mechanisms of emulsification, bioclogging, interfacial tension reduction and wettability alteration have been studied by Ryan and Nabi Vahdanikia. ${ }^{60,61}$ Oil film had almost replaced with water phase in some parts of pore walls after treatment with $E$. cloacae cells. This indicated the main EOR mechanism of E. cloacae cells and its byproducts were wettability alteration. ${ }^{62}$ However, film residual oil remains dominant in the residual oil in this micromodel test. In this experiment, IFT and emulsification were the main mechanism of EOR in this study. IFT reduction is considered to be the most important mechanism of surfactant flooding. ${ }^{63}$ IFT reduction make the residual oil in the pore tend 
to be broken down into small oil droplets. ${ }^{\mathbf{6 4}}$ These enhance oil recovery through improving the sweep efficiency and making residual oil become extremely flexible. ${ }^{65}$ The biosurfactant can separate the crude oil from the oil column and the oil film to form $\mathrm{O} / \mathrm{W}$ emulsion droplets to achieve the goal of EOR. In many biosurfactant micromodel test, IFT reduction and emulsification was the mainly EOR mechanism..$^{\mathbf{6 0 , 6 1}}$

\section{Conclusions}

Indigenous biosurfactant producers isolated from reservoir are often the most appropriate candidates for performing MEOR process. In present work, indigenous biosurfactant-producing strains were isolated from the formation water of the CQ Oilfield in China. Biosurfactant-producing strain Brevibacillus borstelensis YZ-2 was chosen for further study because of its excellent interfacial active. Chromatography methods were used to separate and purify the biosurfactants produced by YZ-2. MALDI-TOF-MS/MS results revealed biosurfactants produced by strain YZ-2 were identified as different isoforms and homologs of fengycin. The biosurfactant production was optimized through Box-Behnken design. The most significant factors influence on the biosurfactant production was the addition of corn steep powder concentration, followed by the addition of $\mathrm{MgSO}_{4}$ and peptone. Core flooding tests were also conducted to further investigate the ability of microorganism toward MEOR process. Results showed that YZ-2 biosurfactant enhance oil recovery by reducing the oil-water IFT and crude oil emulsification.

\section{Conflicts of interest}

There are no conflicts to declare.

\section{Acknowledgements}

This investigation was financially supported by the National Natural Science Foundation of China (51634008, 51804041), Scientific Research Program Funded by Shaanxi Provincial Education Department (Program No. 20JS119).

\section{References}

1 J. Patel, S. Borgohain, M. Kumar, V. Rangarajan, P. Somasundaran and R. Sen, Renew. Sustain. Energy Rev., 2015, 52, 1539-1558.

2 D. M. Ashish, J. Pet. Sci. Eng., 2018, 170, 40-48.

3 F. Gassara, N. Suri, P. Stanislav and G. Voordouw, Environ. Sci. Technol., 2015, 49(20), 12594-12601.

4 E. J. Gudina, J. F. B. Pereira, R. Costa, J. A. P. Coutinho, J. A. Teixeira and L. R. Rodrigues, J. Hazard. Mater., 2013, 261, 106-113.

5 G. Li, P. Gao, Y. Wu, H. Tian, X. Dai, Y. Wang, Q. Cui, H. Zhang, X. Pan, H. Dong and T. Ma, Environ. Sci. Technol., 2014, 48(9), 5336-5344.

6 F. Zhang, Y. She, I. M. Banat, L. Chai, S. Yi, G. Yu and D. Hou, Energy Fuels, 2014, 28(2), 1191-1197.
7 A. E. Elshafie, S. J. Joshi, Y. M. Al-Wahaibi, A. S. Al-Bemani, S. N. Al-Bahry, D. Al-Maqbali and I. M. Banat, Front. Microbiol., 2015, 6, 1324.

8 B. Haq, J. Liu, K. Liu and D. Al Shehri, J. Pet. Sci. Eng., 2020, 189, 106688.

9 A. Rabiei, M. Sharifinik, A. Niazi, A. Hashemi and S. Ayatollahi, Appl. Microbiol. Biotechnol., 2013, 97(13), 5979-5991.

10 G. S. Kiran, S. Priyadharsini, A. Sajayan, G. B. Priyadharsini, N. Poulose and J. Selvin, Front. Microbiol., 2017, 8, 1138.

11 Y. Chen, S. A. Liu, H. Mou, Y. Ma, M. Li and X. Hu, Front. Microbiol., 2017, 8, 871.

12 H. Dong, W. Xia, H. Dong, Y. She, P. Zhu, K. Liang, Z. Zhang, C. Liang, Z. Song, S. Sun and G. Zhang, Front. Microbiol., 2016, 7, 1710.

13 B. Jasim, K. S. Sreelakshmi, J. Mathew and E. K. Radhakrishnan, Microb. Ecol., 2016, 72(1), 106-119.

14 M. S. Kuyukina, I. B. Ivshina, I. O. Korshunova, G. I. Stukova and A. V. Krivoruchko, Amb. Express, 2016, 6, 14.

15 K. Patowary, R. Patowary, M. C. Kalita and S. Deka, Front. Microbiol., 2017, 8, 279.

16 Y. Hsueh, E. B. Somers, D. Lereclus, E. Ghelardi and A. C. L. Wong, Appl. Environ. Microbiol., 2007, 73(22), 72257231.

17 M. Morikawa, H. Daido, T. Takao, S. Murata, Y. Shimonishi and T. Imanaka, J. Bacteriol., 1993, 175(20), 6459-6466.

18 S. Jiao, X. Li, H. Yu, H. Yang, X. Li and Z. Shen, Biotechnol. Bioeng., 2017, 114(4), 832-842.

19 L. Sang-Cheol, S. Kim, I. Park, S. Chung, M. S. Chandra and Y. Choi, Biotechnol. Bioproc. Eng., 2010, 15(2), 246-253.

20 B. C. S. Farias, D. C. Hissa, C. T. M. Do Nascimento, S. A. Oliveira, D. Zampieri, M. N. Eberlin, D. L. S. Migueleti, L. F. Martins, M. P. Sousa, D. N. Moyses and V. M. M. Melo, Appl. Microbiol. Biotechnol., 2018, 102(3), 1179-1190.

21 G. S. Kiran, S. Priyadharsini, A. Sajayan, G. B. Priyadharsini, N. Poulose and J. Selvin, Front. Microbiol., 2017, 8, 1138.

22 D. G. De Almeida, R. D. C. F. Soares Da Silva, J. M. Luna, R. D. Rufino, V. A. Santos, I. M. Banat and L. A. Sarubbo, Front. Microbiol., 2016, 7, 1718.

23 I. M. Banat, A. Franzetti, I. Gandolfi, G. Bestetti, M. G. Martinotti, L. Fracchia, T. J. Smyth and R. Marchant, Appl. Microbiol. Biotechnol., 2010, 87(2), 427-444.

24 R. Marchant and I. M. Banat, Trends Biotechnol., 2012, 30(11), 558-565.

25 I. M. Banat, S. K. Satpute, S. S. Cameotra, R. Patil and N. V. Nyayanit, Front. Microbiol., 2014, 5, 697.

26 P. Das, S. Mukherjee and R. Sen, Bioresour. Technol., 2009, 100(2), 1015-1019.

27 S. N. Al-Bahry, Y. M. Al-Wahaibi, A. E. Elshafie, A. S. AlBemani, S. J. Joshi, H. S. Al-Makhmari and H. S. AlSulaimani, Int. Biodeterior. Biodegradation, 2013, 81(SI), 141-146.

28 E. J. Gudina, E. C. Fernandes, A. I. Rodrigues, J. A. Teixeira and L. R. Rodrigues, Front. Microbiol., 2015, 6, 59.

29 S. N. R. L. Silva, C. B. B. Farias, R. D. Rufino, J. M. Luna and L. A. Sarubbo, Colloids Surf., B, 2010, 79(1), 174-183. 
30 M. Nitschke and G. M. Pastore, Bioresour. Technol., 2006, 97(2), 336-341.

31 D. G. Almeida, R. D. C. F. Soares Da Silva, J. M. Luna, R. D. Rufino, V. A. Santos and L. A. Sarubbo, Front. Microbiol., 2017, 8, 157.

32 R. D. Cássia, F. S. D. Silva, R. D. Rufino, J. M. Luna, C. B. B. Farias, F. Hilario, V. A. D. Santos and L. A. Sarubbo, Tenside Surfact. Det., 2013, 50(2), 137-142.

33 C. Vigneshwaran, V. Sivasubramanian, K. Vasantharaj, N. Krishnanand and M. Jerold, J. Environ. Chem. Eng., 2018, 6, 4347-4356.

34 C. Vigneshwaran, K. Vasantharaj, N. Krishnanand and V. Sivasubramanian, J. Environ. Chem. Eng., 2021, 9, 104867.

35 S. Dhagat and S. Eswari Jujjavarapu, J. Environ. Manage., 2021, 291, 112667.

36 R. Thavasi, S. Jayalakshmi and I. M. Banat, Bioresour. Technol., 2011, 102(3), 3366-3372.

37 I. A. Purwasenaa, D. I. Astutia, M. Syukrona, M. Amaniyaha and Y. Sugaib, J. Pet. Sci. Eng., 2019, 183, 106383.

38 J. Chen, P. T. Huang, K. Y. Zhang and F. R. Ding, J. Appl. Microbiol., 2012, 112(4), 660-671.

39 M. Geissler, C. Oellig, K. Moss, W. Schwack, M. Henkel and R. Hausmann, J. Chromatogr., B, 2017, 1044, 214-224.

40 K. Patowary, R. Patowary, M. C. Kalita and D. Suresh, Front. Microbiol., 2017, 8, 279.

41 X. Hua, Z. Wu, H. Zhang, D. Lu, M. Wang, Y. Liu and Z. Liu, Chemosphere, 2010, 80(8), 951-956.

42 H. Farhadi, S. Ayatollahi and M. Fatemi, J. Pet. Sci. Eng., 2021, 196, 107862.

43 H. Yang, X. Li, X. Li, H. Yu and Z. Shen, Anal. Bioanal. Chem., 2015, 407(9), 2529-2542.

44 A. R. Najafi, M. R. Rahimpour, A. H. Jahanmiri, R. Roostaazad, D. Arabian and Z. Ghobadi, Chem. Eng. J., 2010, 163(3), 188-194.

45 F. Gassara, N. Suri, P. Stanislav and G. Voordouw, Environ. Sci. Technol., 2015, 49(20), 12594-12601.

46 S. J. Joshi, Y. M. Al-Wahaibi, S. N. Al-Bahry, A. E. Elshafie, A. S. Al-Bemani, A. Al-Bahri and M. S. Al-Mandhari, Front. Microbiol., 2016, 7, 1853.

47 B. Dunsmore, C. Bass, C. J. Lappin-Scott and M. Hilary, Environ. Microbiol., 2004, 6(2), 183-187.
48 M. Srikanth Reddy, B. Naresh, T. Leela, M. Prashanthi, N. Ch. Madhusudhan, G. Dhanasri and P. Devi, Bioresour. Technol., 2010, 101, 7980-7983.

49 J. Wang, N. I. A. Haddad, S. Yang and B. Mu, Appl. Biochem. Biotechnol., 2010, 160(3), 812-821.

50 P. Datta, P. Tiwari, M. Lalit and J. Pandey, J. Pet. Sci. Eng., 2020, 195, 107612.

51 K. V. Pathak, H. Keharia, K. Gupta, S. S. Thakur and P. Balaram, J. Am. Soc. Mass Spectrom., 2012, 23, 17161728.

52 A. A. Kaki, N. Smargiasso, M. Ongena, M. K. Ali, N. Moula, E. De Pauw and N. K. Chaouche, Curr. Microbiol., 2020, 77(9), 443-451.

53 S. H. Kim, E. J. Lim, S. O. Lee, J. D. Lee and T. H. Lee, Biotechnol. Appl. Biochem., 2000, 31, 249-253.

54 R. Verma, S. Sharma, L. M. Kundu and L. M. Pandey, J. Water Proc. Eng., 2020, 38, 101632.

55 A. Najafi-Marghmaleki, S. Kord, A. Hashemi and H. Motamedi, Fuel, 2018, 232, 27-35.

56 P. Sarafzadeh, A. Z. Hezave, M. Ravanbakhsh, A. Niazi and S. Ayatollahi, Colloids Surf., B, 2013, 105, 223-229.

57 T. Amirianshoja, R. Junin, A. K. Idris and O. Rahmani, J. Pet. Sci. Eng., 2013, 101, 21-27.

58 W. Yang, J. Lu, B. Wei, H. Yu and T. Liang, ACS Omega, 2021, 6, 6064-6069.

59 B. Hou, Y. Wang, X. Cao, J. Zhang, X. Song, M. Ding and W. Chen, J. Surfactants Deterg., 2015, 19, 315-324.

60 R. T. Armstrong and D. Wildenschild, J. Pet. Sci. Eng., 2012, 94, 155-164.

61 N. Vahdanikia, D. Hassan, A. Hemmati-Sarapardeh, N. Amar Menad, M. Schaffie and M. Ranjbar, J. Pet. Sci. Eng., 2020, 192, 107229.

62 H. Khajepour, M. Mahmoodi, D. Biria and S. Ayatollahi, J. Pet. Sci. Eng., 2014, 120, 10-17.

63 X. Zhao, Y. Feng, G. Liao and W. Liu, J. Colloid Interface Sci., 2020, 578, 629-640.

64 C. G. Ezeh, C.-Y. Chen and K. D. Papadopoulos, Colloids Surf., A, 2018, 558, 123-129.

65 M. Tagavifar, K. Xu, S. H. Jang, M. T. Balhoff and G. A. Pope, Langmuir, 2017, 33(45), 13077-13086. 